\title{
Therapeutic challenges in Management of Subglottic Stenosis in Wegener's Granulomatosis
}

\author{
${ }^{1}$ Nupur Kapoor Nerurkar, ${ }^{2}$ Shraddha Deshmukh
}

\begin{abstract}
Aims and objectives: To report our experience on the treatment of subglottic stenosis (SS) in patients with Wegener's granulomatosis (WG).

Materials and methods: We endoscopically treated five patients with SS due to WG. Out of 5, two patients were treated with endoscopic balloon dilatation, two patients underwent $\mathrm{CO}_{2}$ laser resection and dilatation and 1 patient underwent a cold steel resection and dilatation. Outcomes were assessed based on improvement in preoperative symptoms, complications, and need for additional procedures.
\end{abstract}

Results: Balloon dilatation was done in two patients. They are asymptomatic at follow-up and the one with tracheostomy is in the process of decannulation. The other two patients were treated with $\mathrm{CO}_{2}$ laser. Favorable outcome was obtained in one of the patient who is in the process of decannulation, the other developed recurrent stenosis at 3 years and is on tracheostomy. Cold steel resection was used to treat one patient. After undergoing multiple interventions, she developed severe stenosis and underwent an open procedure and is currently on tracheostomy.

Conclusion: Both use of balloon and laser resection are safe and successful method to manage soft, subglottic stenosis due to WG and avoids the need of open procedure. In our series balloon dilatation gave better outcomes as compared to Laser resection and dilatation. Regular follow-up is necessary to rule out recurrence.

Keywords: Larynx, Carcinoma, Voice.

How to cite this article: Nerurkar NK, Deshmukh S. Therapeutic challenges in Management of Subglottic Stenosis in Wegener's Granulomatosis. Int J Phonosurg Laryngol 2014;4(2):76-79.

Source of support: Nil

Conflict of interest: None

\section{INTRODUCTION}

Subglottic stenosis (SS) is a significant complication of Wegener's granulomatosis (WG), which if left untreated, can be potentially life-threatening. Noteworthy is the fact

\footnotetext{
${ }^{1}$ Consultant Laryngologist, ${ }^{2}$ Ex Clinical Fellow

${ }^{1}$ Department of ENT, Bombay Hospital, Mumbai, Maharashtra, India

${ }^{2}$ Department of ENT, Seth GS Medical College and KEM Hospital, Mumbai, Maharashtra, India
}

Corresponding Author: Nupur Kapoor Nerurkar, Consultant Laryngologist, Department of ENT, Bombay Hospital, Mumbai Maharashtra, India, e-mail: nupurkapoor@yahoo.com that frequently, it occurs independently of other features of active disease, ${ }^{1}$ and may appear while the general disease is in remission. Thus a high index of suspicion is required to establish this diagnosis. The management of subglottic stenosis is challenging as often it is not responsive to immunosuppressant therapy. ${ }^{2}$ Thus, an individualized approach that includes medical and interventional therapy is recommended and we report our experience on the endoscopic management of SS with WG.

\section{MATERIALS AND METHODS}

We treated five patients of SS with WG (Table 1). All five patients were females, with a mean age of 25 years. All patients were positive for c-ANCA according to blood tests. The main presenting complaint was dyspnea on exertion. The patients were evaluated by computed tomography scan, chest X-ray and routine blood tests. Preoperative fibreoptic laryngoscopy and bronchoscopy provided valuable information regarding level and extent of stenosis. All patients were treated by immunosuppressive agent. Inspite of the disease being in the remission phase with good systemic disease control, these patients had developed dyspnea on exertion. Three patients had a preoperative tracheostomy.

\section{SURGICAL PROCEDURE}

\section{Cold Steel Resection}

Direct microlaryngoscopy was performed under general anesthesia in one patient. She had a tracheostomy tube in situ. Using a laryngoscope, the glottis and subglottic areas were exposed. A microscope with a $400 \mathrm{~mm}$ objective lens was used. Lysis of the stenotic ring was then performed by making circumferential triradiate incisions with cold steel instruments. The stenosis was then serially dilated with bougies. Next, methylprednisolone $60 \mathrm{mg}$ was injected submucosally and then mitomycin $4 \mathrm{mg} / \mathrm{ml}$ was applied with cottonoid at the local site.

\section{Laser Resection and Dilatation}

Direct microlaryngoscopy was performed under general anesthesia in two patients (one patient had a tracheostomy tube in situ, in the other a laser safe endotracheal tube was used). Using a laryngoscope, the glottis and 


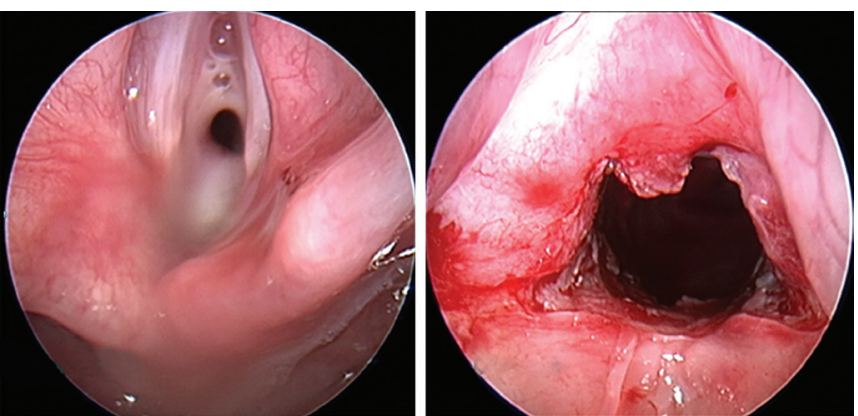

Fig. 1: Pre- and postoperative results of laser resection and dilatation of subglottic stenosis

subglottic areas were exposed. A microscope with a 400 $\mathrm{mm}$ objective lens coupled to a $\mathrm{CO}_{2}$ laser was used in both cases. The laser setting was $10 \mathrm{~W}$ in a Superpulse mode. Moistened patty was placed in subglottic area to protect the endotracheal tube and the trachea during excision of the stenosis. Lysis of the stenotic ring was then performed by making circumferential triradiate incisions with laser (Fig. 1). The stenosis was then serially dilated with bougies. Next, methylprednisolone $60 \mathrm{mg}$ was injected submucosally and then mitomycin $4 \mathrm{mg} / \mathrm{ml}$ was applied with cottonoid at the local site.

\section{Balloon Dilatation}

Direct laryngoscopy was performed under general anesthesia in two patients (one patient had a tracheostomy tube in situ, the other was intubated with a number 5 portex endotracheal tube). Under direct telescopic visualization an airway balloon catheter, $40 \times 10 \mathrm{~mm}$ was inserted in the stenotic segment (Fig. 2). The balloon was then inflated to a pressure of $12 \mathrm{~atm}$ using a syringe with an attached pressure gauge. Pressure was maintained for sometime, then the balloon was deflated and an endotracheal tube was inserted into the dilated airway for oxygenation and then removed to perform the bronchoscopy. Next, methylprednisolone $60 \mathrm{mg}$ was injected submucosally and then mitomycin $4 \mathrm{mg} / \mathrm{ml}$ was applied with cottonoid at the local site.

\section{RESULTS}

We treated five patients of SS with WG (Table 1). The patient with cold steel resection required 8 interventions. Subsequently she developed a complete stenosis and underwent an open procedure and a Montgomery stent was put. She was asymptomatic for a period of 3 months
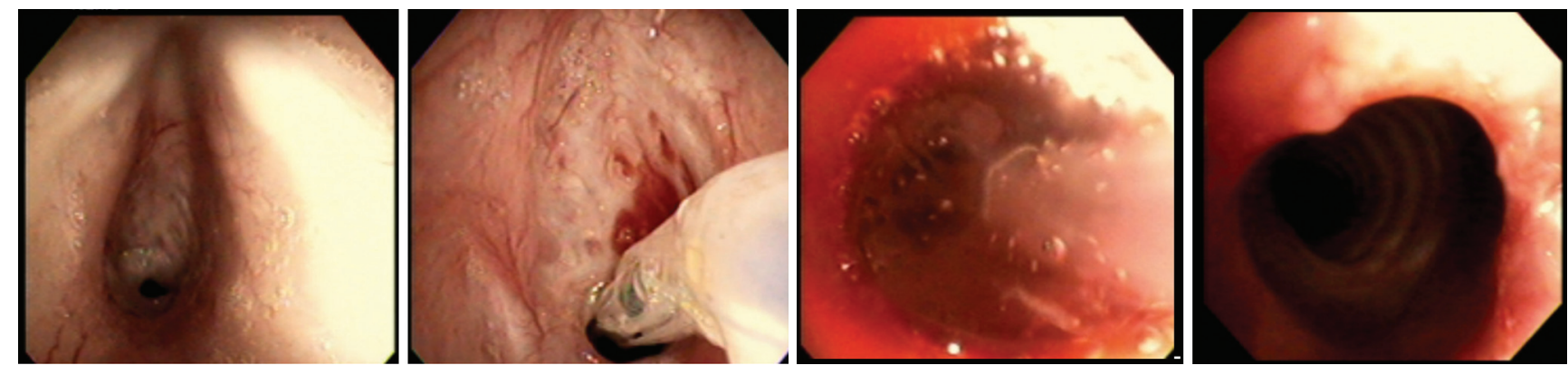

Fig. 2: Pre- and postoperative results of balloon

Table 1: Summary of treatment and outcomes in five cases of Wegener's granulomatosis with subglottic stenosis

\begin{tabular}{|c|c|c|c|c|c|c|c|}
\hline & $\begin{array}{l}\text { Site of } \\
\text { stenosis }\end{array}$ & $\begin{array}{l}\text { Grade of } \\
\text { stenosis } \\
\text { (Cotton-Myer } \\
\text { grading) }\end{array}$ & $\begin{array}{l}\text { Preoperative } \\
\text { tracheostomy }\end{array}$ & Procedure & Interventions & Outcome & Follow-up \\
\hline 1. & Subglottis & III & Yes & $\begin{array}{l}\text { Cold steel } \\
\text { resection }\end{array}$ & 8 & $\begin{array}{l}\text { Developed severe stenosis and } \\
\text { underwent open procedure. } \\
\text { Asymptomatic for } 3 \text { months } \\
\text { but developed severe stenosis } \\
\text { requiring tracheostomy }\end{array}$ & 5 years \\
\hline 2. & Subglottis & II & No & $\begin{array}{l}\text { Balloon } \\
\text { dilatation }\end{array}$ & 2 & $\begin{array}{l}\text { Favorable, no tracheostomy, } \\
\text { good voice }\end{array}$ & 1 year \\
\hline 3. & $\begin{array}{l}\text { Subglottis } \\
\text { tracheal } \\
\text { suprastomal }\end{array}$ & III & Yes & $\begin{array}{l}\text { Balloon } \\
\text { dilatation }\end{array}$ & 4 & $\begin{array}{l}\text { Favorable, tolerating blocked } \\
\text { tracheostomy tube, awaiting } \\
\text { decannulation }\end{array}$ & 4 years \\
\hline 4. & Subglottis & II & No & $\begin{array}{l}\text { Laser+ } \\
\text { Balloon }\end{array}$ & 2 & $\begin{array}{l}\text { Required tracheostomy then } \\
\text { balloon dilatation, tolerating } \\
\text { blocked tube }\end{array}$ & 1 year \\
\hline 5. & Subglottis & III & Yes & $\begin{array}{l}\text { Laser } \\
\text { resection and } \\
\text { dilatation }\end{array}$ & 3 & $\begin{array}{l}\text { Good for } 1 \text { year, then required } \\
\text { tracheostomy, underwent two } \\
\text { more interventions }\end{array}$ & 3 years \\
\hline
\end{tabular}


but then again developed a complete stenosis with no voice. This patient was the earliest on in our series of patients.

Balloon dilatation was done in two patients. Of the two patients of balloon dilatation, ${ }^{1}$ had single level of subglottic stenosis and the other had three levels of subglottic and tracheal stenosis with a tracheostomy in situ. We could achieve favorable outcomes in both the patients with one requiring one more serial dilatation, she is without any tracheostomy and has a good voice. The other patient with multilevel stenosis and preoperative tracheostomy required 4 serial dilatations, post which she is tolerating the tube block well and is in the process of decannulation.

The other two patients were treated with $\mathrm{CO}_{2}$ Laser resection and dilatation. Of the two, one patient came in stridor within 1 month and required tracheostomy. Subsequently she underwent a balloon dilatation and is asymptomatic at follow-up and is tolerating tube block intermittently. The second patient was asymptomatic for 1 year after which she required a tracheostomy. She underwent 2 more interventions and currently her tube is blocked for the past 4 months.

Of the two patients, one patient underwent one more intervention and the other patient underwent three serial interventions. Favorable outcome was obtained in one of the patient who is in the process of decannulation, the other developed recurrent stenosis at 3 years and is on tracheostomy.

In our series thus patients with balloon dilatation are doing better as compared to laser resection and dilatation.

\section{DISCUSSION}

Subglottic stenosis occurs in 16 to $23 \%$ of the patients with WG. ${ }^{1,3,4}$ This complication seems to be more common in the younger age group. ${ }^{5}$ The average age of the patients in our series was 25 years.

The pathogenesis is unclear. It is postulated that during flares of systemic disease, subclinical subglottic involvement occurs, which subsequently heals with circumferential scarring. The subglottis area is susceptible to symptomatic narrowing due to the complete ring of cricoids cartilage, whereas the lower trachea has a fibromembranous posterior wall. ${ }^{6}$

It has been reported that the clinical course of SS runs independent of the systemic WG activity. SS can be present in absence of an active disease. ${ }^{1}$ If left untreated, patients with SS due to WG are at a great risk of severe airway obstruction.

The stenosis can be graded using the Cotton-Myer classification of grading circumferential SS (Table 2).

Wegener's granulomatosis can be confirmed on histopathology findings of vasculitis, necrotising granulomas
Table 2: Cotton-Myer's classification originally proposed for pediatric subglottic stenosis ${ }^{6,7}$

\begin{tabular}{lll}
\hline Classification & From & To \\
\hline Grade I & No obstruction & $50 \%$ obstruction \\
Grade II & $51 \%$ obstruction & $70 \%$ obstruction \\
Grade III & $71 \%$ obstruction & $99 \%$ obstruction \\
Grade IV & No detectable lumen & \\
\hline
\end{tabular}

and giant cells. But, in general, biopsies of subglottic lesions are inconclusive and donot demonstrate the typical picture. ${ }^{1,8}$

Subglottic stenosis with WG poorly responds to medical management, the success rates of medical therapy in relieving the obstruction vary from 22 to $26 \%{ }^{1,8} \mathrm{~A}$ surgical intervention is required when patients continue to complain of respiratory distress. Tracheostomy, major open procedures, endoscopic laser surgery, balloon dilatation, airway stents, are the possible surgical interventions.

With the advent of high-pressure airway balloons, balloon laryngoplasty has been increasingly used for treatment of subglottic stenosis. It causes minimal mucosal trauma and causes effective dilatation. Serial balloon dilations may be needed and open procedures may be avoided in some patients. Shvero et $\mathrm{al}^{5}$ treated 5 cases of SS with Laser. For lesions close to the vocal cords, in 2 patients, $\mathrm{CO}_{2}$ laser was used. For lesions far from the cords, i.e. more than $1 \mathrm{~cm}$, in 3 patients, $\mathrm{Nd}$ :YAG laser was used. Out of the 5,4 patients are reported to have favorable outcomes or decannulation. One patient required open procedure and a subglottic stent. Balloon dilatation and laser resection ${ }^{7}$ with dilatation are safe and effective methods to deal with soft stenosis associated with WG and give favorable outcomes. In our series balloon dilatation gave better results compared to laser resection and dilatation.

Both balloon dilatation and laser resection and dilatation are effective in managing the soft stenosis. Inralesional corticosteroid injection and dilatation is an effective management of SS in WG. ${ }^{8}$ Mitomycin seems to postpone, but does not prevent, the recurrence of symptomatic stenosis in the majority of patients. ${ }^{9}$

Potential limitations of the present study include small sample size, retrospective nature of the study, and lack of a control group.

\section{CONCLUSION}

1. Strongly consider the diagnosis of SS in any patient with a known history of WG who presents with dyspnea.

2. Subglottic stenosis may develop or progress when the general disease is under remission. 
3. Most often it will not respond to conventional immunosuppressant therapy and a combination of medical and interventional therapy is recommended.

4. Subglottic stenosis due to WG should be dealt with in a kid glove manner and an individualized approach including local therapy and interventional treatment is recommended.

5. Balloon dilatation and laser resection with dilatation are safe and effective methods to deal with soft stenosis associated with WG and give favorable outcomes.

\section{REFERENCES}

1. Gluth MB, Shinners PA, Kasperbauer JL. Subglottic stenosis associated with Wegener's Granulomatosis. Laryngoscope 2003;113:1304-1307.

2. Strange C, Halstead L, Baumann M, Sahn SA. Subglottic stenosis in Wegener's granulomatosis: development during cyclophosphamide treatment with response to carbon dioxide laser therapy. Thorax 1990;45(4):300-301.
3. O'Devaney K, Ferlito A, Hunter BC, Devaney SL, Rinaldo A. Wegener's granulomatosis of the head and neck. Ann Otol Rhinol Laryngol 1998;107:439-445.

4. DeRemee RA, McDonald TJ, Harrison EG, Coles DT. Wegener's granulomatosis. Anatomic correlates, a proposed classification. Mayo Clin Proc 1976;51:777-781.

5. Shvero J et al. Laser surgery in subglottic stenosis and Wegeners disease. Yonsei Med J 2007;48(5):748-753.

6. Blaivas AJ et al. Subglottic stenosis as a complication of Wegeners Granulomatosis. Primary Care Respiratory J 2008;17(2):114-116. Yates PD. Stridor in Children, In: Lalvani AK, Current Diagnosis and treatment in otolaryngology head and neck surgery (2nd ed), New York, McGraw Hill, 2008;462-474. (cited 2012 April 16)

7. Monnier P, George M, Marie-Laure Monod, Lang F. The role of $\mathrm{CO}_{2}$ Laser in the management of laryngotracheal stenosis: a survey of 100 cases. Eur Arch Otorhinolaryngol 2005;262:602-608.

8. Langford CA, Sneller MC, Hallahan CW, et al. Clinical features and therapeutic management of subglottic stenosis in patients with Wegener's granulomatosis. Arthritis Rheum 1996;39(10):1754-1760.

9. Solans-Laqué R. Clinical characteristics and treatment of Subglottic stenosis in patients with Wegener's Granulomatosis. Int J Clin Rheum 2010;5(4):475-486. 